\title{
FORMAS PLURAIS DE GOVERNANÇA: UMA ANÁLISE DAS TRANSÇÕES ENTRE LATICÍNIOS E PRODUTORES NA REGIÃO OESTE DO PARANÁ
}

Plural forms of governance: an analysis of transaction between dairy products and producer in west region of Paraná

DOI: 10.48075/igepec.v25i1.25889

Victoria Maria Ferreira Diniz

Carla Maria Schmidt

Ivanete Daga Cielo 


\title{
FORMAS PLURAIS DE GOVERNANÇA: UMA ANÁLISE DAS TRANSAÇÕES ENTRE LATICÍNIOS E PRODUTORES NA REGIÃO OESTE DO PARANÁ
}

\author{
Plural forms of governance: an analysis of transactions between dairy products \\ and producer in west region of Paraná
}

DOI: $10.48075 /$ igepec.v25i1.25889

Victória Maria Ferreira Diniz Carla Maria Schmidt Ivanete Daga Cielo

\begin{abstract}
Resumo: A abordagem teórica das formas plurais das transações propõe a possibilidade de que as firmas utilizem duas ou mais formas de organização para a mesma transação. Nesse sentido, o objetivo deste trabalho foi identificar a existência de formas plurais nas transações entre os laticínios e os fornecedores de leite na região Oeste do Paraná e analisar os determinantes para a escolha dessas estruturas alternativas de organização da transação. Para isso, foi realizado um estudo qualitativo de carácter descritivo por meio de entrevistas realizadas com integrantes do elo agroindústria, totalizando 12 laticínios entrevistados. Os principais resultados indicam que 66\% dos laticínios analisados adotam formas plurais para coordenar suas transações de compra de leite. O que permitiu inferir que as firmas procuram estabelecer mais de uma forma de aquisição de leite, buscando minimizar a incerteza.
\end{abstract}

Palavras-Chaves: Formas plurais, estrutura de governança, bovinocultura leiteira.

\begin{abstract}
The theoretical approach of plural forms of organization of transactions proposes the possibility that firms use two or more forms for the same transaction. In this sense, the objective of this work was to identify the existence of plural forms in the transactions between milk industries and producers in the western region of Paraná and to analyze the determinants for the choice of these alternative structures of organization of the transaction. For this, a qualitative study of a descriptive character was carried out through interviews with members of the agribusiness link, totaling 14 dairy products interviewed. The main results indicate that 66\% of the analyzed dairy products adopt plural forms to coordinate their milk purchase transactions. This allowed us to infer that firms seek to establish more than one form of milk acquisition, seeking to minimize uncertainty.
\end{abstract}

Key-words: Plural forms, governance structure, dairy products.

Resumen: El presente trabajo tuvo como objetivo identificar indicadores predictivos para el precio de las acciones de las empresas del sector agropecuario en B3, a través del análisis por múltiplos. Los datos de las empresas se recopilaron a través de lo software Economática, en el período de 2011 a 2015, en el que se realizaron análisis de regresión lineal múltiple. Los resultados mostraron que indicadores como Liquidez Corriente (LC) y Valor Patrimonial por Acción (VPA) tienen mayor capacidad para predecir el valor de las acciones de las organizaciones investigadas. Como resultado, los múltiples del análisis fundamental, especialmente aquellos con representación directa, demuestran una capacidad efectiva para predecir el valor de la empresa en términos de acciones, guiando las decisiones de inversión. El estudio contribuyó al análisis de los múltiplos dentro del sector agropecuario, cuya capacidad predictiva demostró ser útil para verificar cuánto el valor patrimonial por acción es equivalente al precio de la acción negociado en el mercado.

Palabras clave: formas plurales, estructura de gobierno, ganado lechero. 
Informe GEPEC, ISSN: 1679-415X, Toledo, v. 25, n.1, p. 240-260, jan./jun. 2021. 


\section{INTRODUÇÃO}

O leite é um dos principais produtos da agropecuária brasileira, o que faz com que o país seja o quarto maior produtor de leite do mundo ${ }^{1}$, com um volume de 33 milhões de toneladas, ficando atrás somente da Índia (201 milhões de toneladas), Estados Unidos (95 milhões de toneladas) e Paquistão (48 milhões de toneladas) de acordo com os dados publicados pelo Anuário do Leite 2020 (EMBRAPA, 2020). Para produzir esse montante existe, de acordo com o Censo Agropecuário de 2017, 1,17 milhão de estabelecimentos produtores de leite no Brasil, o que representa $22 \%$ das propriedades rurais. Ademais, $58 \%$ do leite produzido no país é oriundo da agricultura familiar.

O estado do Paraná é o segundo maior produtor de leite do país, com volume de 4,3 bilhões de litros em 2019 e é responsável por 13\% dos estabelecimentos produtores de leite do país. A região Oeste, foco deste estudo, é uma das maiores produtoras de leite do estado, sendo responsável por $19 \%$ da produção estadual, representando 816.055 mil litros de leite em 2019. Também possui 20\% de todos os estabelecimentos produtores de leite do estado sendo a segunda maior bacia leiteira. A região se destaca ainda por possuir uma das maiores receptoras de leite do Brasil, o que contribui para o aumento da produção nos municípios da região Oeste de acordo com a Embrapa (IPARDES, 2019; IBGE, 2017).

Embora a atividade venha demonstrando seu potencial e oportunidade de crescimento, verifica-se que é necessário superar alguns gargalos. Observa-se no cenário nacional a existência de produção informal destinada à comercialização clandestina e ao consumo próprio. No Brasil, esse gargalo representa quase 1/3 da produção leiteira nacional, ou seja, 6,3 milhões de litros no primeiro trimestre de 2020 (IBGE, 2020). A informalidade presente na atividade pode contribuir para que haja comportamentos oportunistas, se tornando um potencial problema à saúde pública devido à ausência de uma inspeção higiênico-sanitária adequada (FARINA et al., 2000; MARTINS, 2004; SOUZA; PEREIRA, 2009).

Outro gargalo a ser superado diz respeito a necessidade de adoção de mecanismos para potencializar os ganhos competitivos e de coordenação eficiente entre os elos do sistema agroindustrial (SAG). As ligações presentes entre os elos passam a ser vistos como espaços importantes para análises estratégicas (CAMPEÃO, 2004). Por esse motivo, a forma como os recursos físicos, financeiros e informações fluem entre os elos são considerados fatores decisivos para o sucesso de todos os envolvidos na transação. Para Mendes (1999), a visão de ambiente sistêmico exige que as empresas busquem formas de organização para serem capazes de sobreviver diante de incertezas e riscos. A coordenação de ações entre os segmentos que compõem o SAG seriam então, itens para que esta se torne mais competitivo.

A análise econômica de modos alternativos de organização de estruturas de governança tem sido tema recorrente de discussão e investigação na área da Economia. Iniciada por Coase (1937), o estudo sobre a Economia dos Custos de Transação (ECT) perpassou pela discussão dos limites da firma e de diferentes formas de organização/coordenação, além de discutir o trade-off entre a decisão sobre fazer ou comprar como elemento que definiria os limites da firma. Com essa discussão, o debate teórico passar a ter espaço para o estudo de diferentes arranjos contratuais possíveis para organizar as transações.

\footnotetext{
${ }^{1} \mathrm{O}$ anuário se baseia em dados de 2018.
} 
Bradach e Eccles (1989) introduziram formalmente o termo plural alegando que se tratava de um arranjo em que distintos mecanismos de controle organizacionais são operados simultaneamente para a mesma função na mesma empresa. As empresas frequentemente combinam modos alternativos de governança para o mesmo tipo de transação dentro de um determinado ambiente institucional (SCHNAIDER et al., 2014).

Nesse sentido, este trabalho teve por objetivo identificar a existência de formas plurais nas transações entre os laticínios e os fornecedores de leite na região Oeste do Paraná e analisar os determinantes para a escolha dessas estruturas alternativas de organização da transação- A escolha do SAG do leite está relacionada com a sua importância para o agronegócio brasileiro, além de contribuir com estudos para essa atividade nas regiões do Brasil. Breitenbach (2012) aponta que o baixo número de pesquisas realizadas sobre estruturas de governança na bovinocultura leiteira das regiões brasileiras não permite o mapeamento detalhado das mesmas e isso dificulta a compreensão sistêmica da atividade.

\section{REVISÃO DE LITERATURA}

Ao longo das últimas décadas a Teoria da Organização evoluiu e incorporou em seu escopo aspectos que incluem modos de governança que não são nem da forma de mercado nem organizações integradas. Esses modelos permitiram o desenvolvimento de uma abordagem que discute a decisão sobre fazer ou comprar, o que representou um avanço no campo da organização industrial. Isso porque buscou-se a compreensão da realidade na qual as organizações estão inseridas, que apresentaram um quadro cada vez mais complexo de variedades de arranjos (MÉNARD, 2014).

Ao invés de optarem por apenas uma forma de coordenação, as firmas podem usar duas ou mais formas simultaneamente para a mesma transação (MÉNARD, 2014). Para Mello e Paulillo (2010) e Silveira et al. (2014), as formas plurais podem emergir em diferentes contextos e transações, sendo possível encontrar uma variedade de argumentos que contribuem na explicação desse fenômeno. Esses argumentos são classificados em três grupos e descritos a seguir.

Para o primeiro, as formas plurais são resultantes das diferenças dos atributos das transações, pois, os mecanismos que governam as transações precisam estar adequados aos atributos da transação (incerteza, especificidade de ativos e frequência) tendo como base o modelo de Williamson (1991). O modelo teórico proposto por Ménard (2014) adicionou o atributo ambiguidade, que surge devido à dificuldade de analisar especificidade dos ativos no momento de realizar a transação.

Para o segundo, as formas plurais são uma situação transitória e no longo prazo prevalecerá a estrutura de governança mais eficiente. As formas plurais de governança podem ser explicadas pela existência de rotinas específicas e intransferíveis e pelas diferenças no ambiente institucional no qual as transações se processam, as quais criam barreiras para a difusão de uma estrutura de governança superior (ZANELLA, 2017).

Para o terceiro, as formas plurais são estáveis. Bradach e Eccles (1989) propuseram que as formas plurais estão relacionadas ao uso de uma forma de governança para gerenciar a outra. Por exemplo, as firmas podem adotar contratos a termo para fazer hedge de preço e garantir a venda de parte da escala de produção e, ao mesmo tempo, vender o excedente da produção no mercado spot, buscando, como isso, aproveitar-se das vantagens que esse mecanismo também pode proporcionar (SILVEIRA et al., 2014). 
Ménard et al. (2014) complementam essa discussão, afirmando que as formas plurais são estáveis e não transitórias. Propõem então um modelo que consideram ser uma versão substancialmente revista do modelo da ECT de Williamson $(1985,1991$, 1996). O modelo proposto pelos autores considerou três possíveis determinantes da adoção de formas plurais nas transações: ambiguidade, complexidade e comportamento estratégico.

Sobre a ambiguidade, Silveira et al. (2014), conceituou-a como a dificuldade de avaliar corretamente o benefício esperado ao lidar com as características das transações. A ambiguidade, assim como a sua intensidade, pode ser determinada pela imprevisibilidade da oferta e demanda. Logo, em situações nas quais os benefícios trazidos pelo uso de uma ou outra solução não são claros, opta-se por usar um conjunto de estruturas alternativas, visando solucionar o problema da imprevisibilidade que é o elemento central da ambiguidade. Em alguns setores, como no agronegócio, a perecibilidade dos produtos aumenta a imprevisibilidade, ocasionando a utilização de soluções alternativas e, neste caso, as formas plurais de governança podem determinar a capacidade da empresa em manter seus compromissos, tais como a qualidade e quantidade acordadas contratada (SILVEIRA et al., 2015; ZANELLA, 2017).

A complexidade, outro determinante do modelo de Ménard et. al. (2014), está atrelada às características tecnológicas ou organizacionais presentes na transação. Essa complexidade deve ser organizada por uma das partes e está relacionada à possibilidade de existência de incerteza sobre a forma mais adequada para monitorar determinada operação. E, por fim, o comportamento estratégico que acontece quando uma das partes da transação define a estrutura de governança, por meio do uso de um arranjo plural, no intuito de maximizar a captura de renda envolvida (MÉNARD, 2014).

A questão central ligada às três variáveis do modelo apresentado por Ménard et. al. (2014) é que a principal força por trás da escolha das formas plurais é a incerteza relacionada às transações que estão em jogo. Isso pois, as transações compartilham níveis e características semelhantes quando se trata da especificidade de investimentos e são repetidas de forma que a frequência não é um fator de diferenciação (MÉNARD et al., 2014).

\section{PROCEDIMENTOS METODOLÓGICOS}

Esta pesquisa pode ser caracterizada como qualitativa e descritiva. No que se refere à abordagem qualitativa, ela se caracteriza por ser livre, ou seja, permitir que aconteça alterações durante o seu desenvolvimento. Isso ocorre porque a pesquisa qualitativa parte de questões mais amplas, as quais vão sendo esclarecidas durante o processo da pesquisa (GODOY, 1995; BREICHBAND, 2012).

A realização de um estudo descritivo tem por objetivo descrever as características de uma determinada população, estabelecendo-se assim, relações entre as variáveis (GIL, 2009; 2010). No caso deste estudo, o intuito foi descrever como os agentes, a indústria e o produtor, relacionam-se de acordo com a estrutura de governança adotada. Com isso, foi possível compreender qual era a estrutura de governança adotada pelos laticínios para realizar transações com fornecedores de leite, considerando a existência das formas plurais, o contexto, a motivação e outros fatores para adoção dessas estruturas.

Este trabalho foi desenvolvido no Oeste do Paraná, um dos principais polos agrícolas do país dos últimos 50 anos. A região se destaca pela concentração de produção agropecuária, com aptidão para avicultura comercial, suinocultura, bovinocultura de leite e piscicultura. Também é uma das maiores produtoras de grãos

Informe GEPEC, ISSN: 1679-415X, Toledo, v. 25, n.1, p. 240-260, jan./jun. 2021. 
com destaque para soja e milho, informação corroborada pelos seguintes dados: o Paraná produziu 20.498,9 (mil ton) de soja primeira safra em 2020, e a região Oeste produziu 19\% desse total. Em relação a produção de milho, o Paraná produziu 3.457,4 (mil ton) de milho primeira safra em 2020, sendo a região Oeste responsável por 8\% desse total (mil ton) (SEAB/DERAL, 2020). A região é constituída por 50 municípios conforme a Figura 1.

Figura 1 - Localização da região Oeste do Paraná

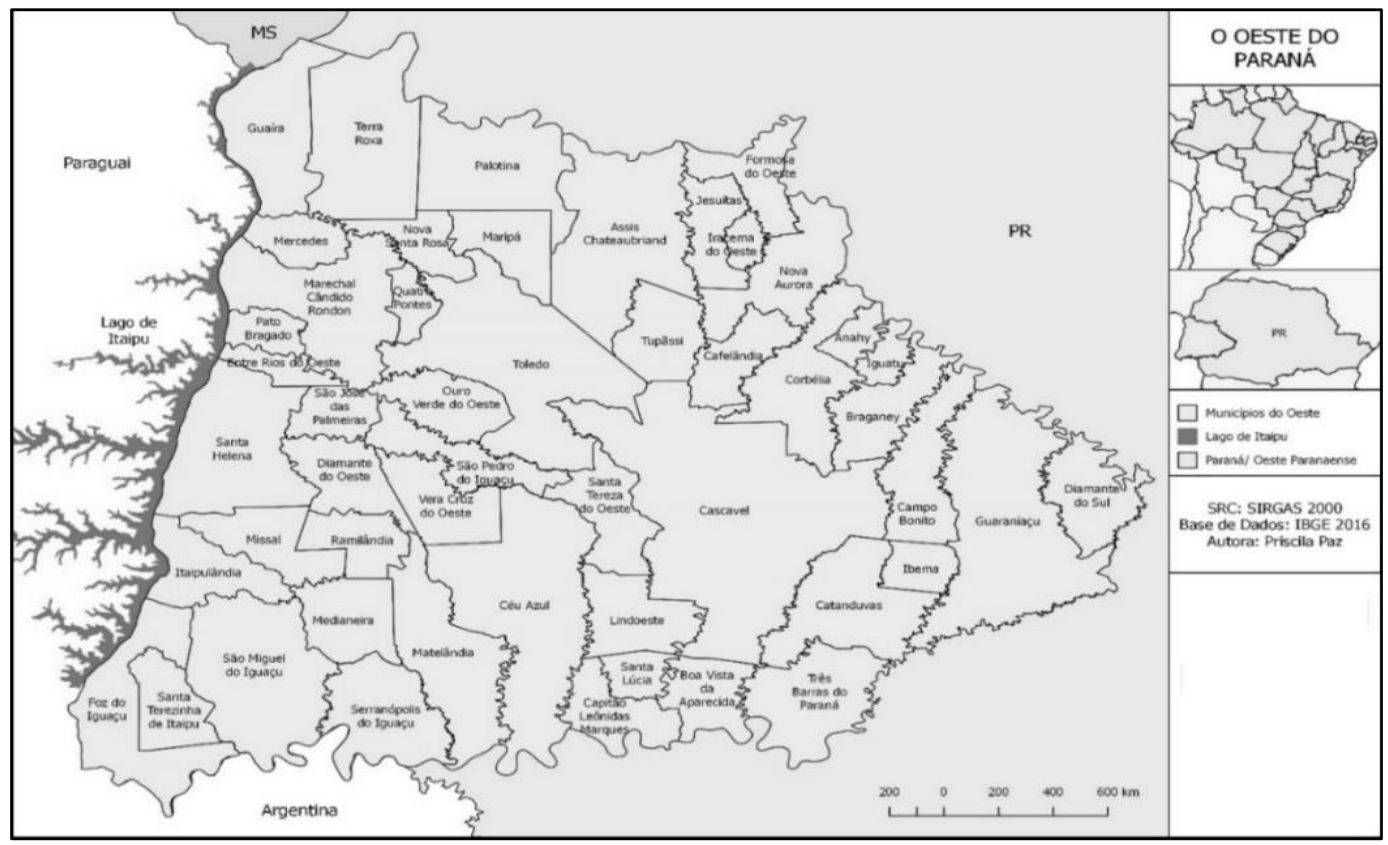

Fonte: IBGE (2016).

Este trabalho utilizou a base de informações da Agência de Defesa Agropecuária do Paraná (ADAPAR, 2018) para identificar os agentes que foram entrevistados. Foram selecionados apenas os estabelecimentos que possuem Serviço de Inspeção Federal (SIF) nos municípios da região Oeste do Paraná para fazer parte da amostra desse estudo.

O SIF é responsável por assegurar a qualidade de produtos de origem animal comestíveis e não-comestíveis destinados ao mercado interno e externo e o mercado de produtos importados. A adoção desse tipo de sistema de inspeção se deve a possibilidade de obter maior nível de exigência quanto aos parâmetros de qualidade da matéria prima processada. Destaca-se ainda que se entende por leite, sem outra especificação, o produto oriundo da ordenha completa, ininterrupta, em condições de higiene, de vacas sadias, bem alimentadas e descansadas, segundo o Decreto $\mathrm{n}^{0}$ 9.013 (BRASIL, 2017). Cabe complementar que os sistemas de inspeção têm como propósito assegurar a segurança sanitária do alimento que está sendo produzido, o SIF considerado o mais exigente, pois os produtos desse sistema possuem diversos destinos (MAPA, 2017).

Desse modo, este trabalho parte da premissa que estabelecimentos com este selo de inspeção possuem maior monitoramento da matéria prima e seus produtores uma especificidade maior do leite, já que eles têm um nível maior de exigência. Esse cenário causa interesse na própria indústria em manter relações com esses produtores/fornecedores que possuem matéria prima que atenda aos padrões exigidos pelo SIF. 
Identificou-se na região 14 estabelecimentos industriais de leite e derivados que são denominados de fábricas de laticínios. Essa denominação é utilizada para estabelecimentos destinados ao recebimento de leite e de creme para o preparo de quaisquer produtos de laticínios, segundo o Decreto $\mathrm{n}^{0}$ 9.013, no artigo 21, que classifica estabelecimentos de leite e derivados (BRASIL, 2017). Na Figura 2 visualizase a localização dos estabelecimentos industriais de leite e derivados com SIF na região Oeste do Paraná.

Figura 2 - Estabelecimentos com SIF na região Oeste do Paraná

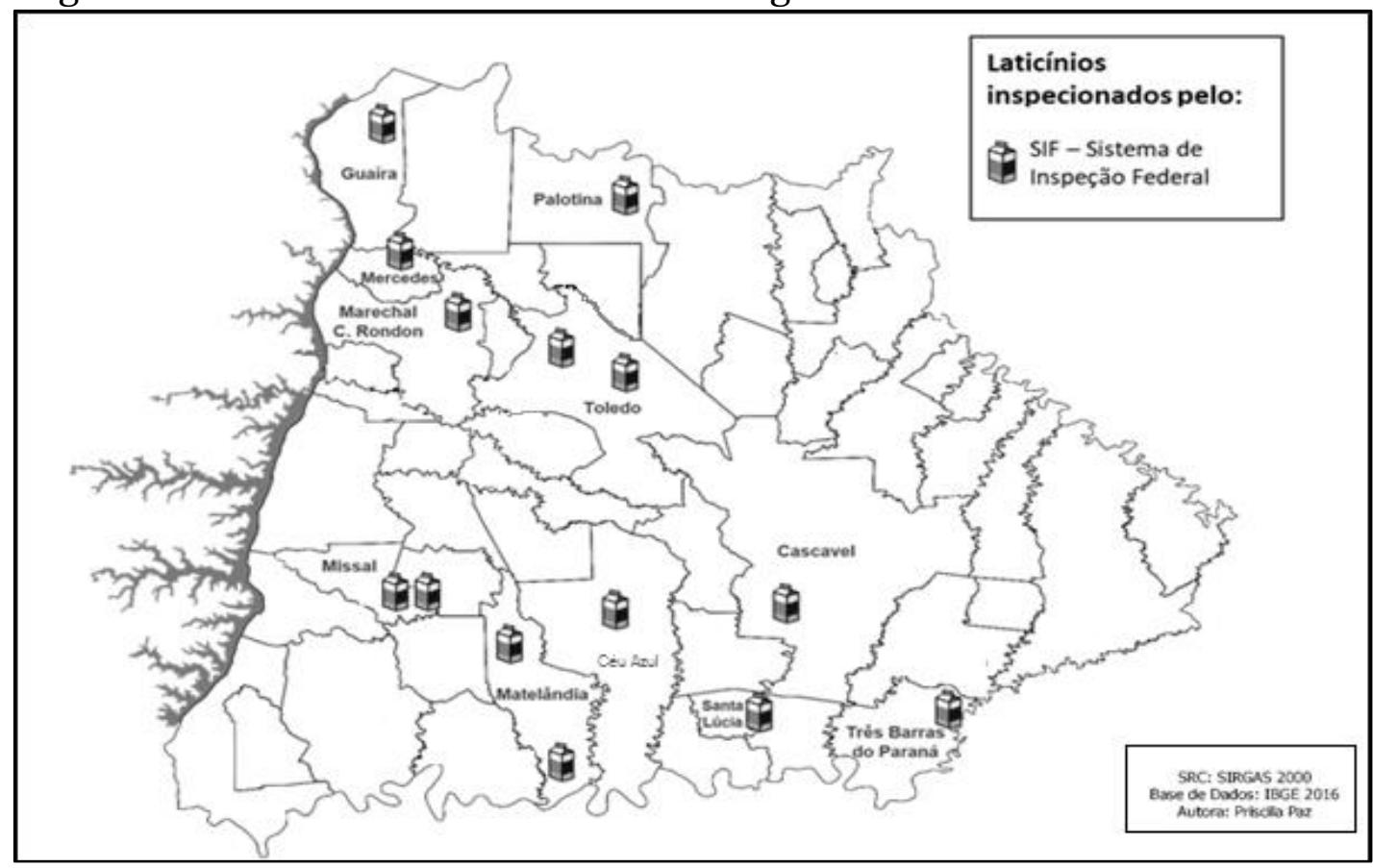

Fonte: ADAPAR (2018).

Conforme verificado na Figura 2, Missal possui dois laticínios; Marechal Candido Rondon, Toledo, Cascavel, Céu Azul, Santa Lucia, Três Barras do Paraná, Maripá, Matelândia, Palotina, Guaíra, Quatro Pontes e Mercedes possuem um laticínio cada. Dos 14 laticínios identificados por meio do relatório da Adapar, 12 foram entrevistados. Assim, o foco deste estudo estará nesses 12 laticínios que estão presentes em onze municípios da região. Para atingir os objetivos propostos, este trabalho apresentou cinco etapas sucessivas, descritas a seguir.

A primeira etapa foi destinada a construção da base teórica no intuito de identificar as teorias que nortearam esta pesquisa empírica e a seleção das variáveis de interesse a serem utilizadas. As principais teorias que nortearam esse trabalho foram a Economia dos Custos de Transação (ECT) e das formas plurais. As variáveis analisadas na transação foram: racionalidade limitada, oportunismo, especificidade do ativo, frequência da transação e incerteza da transação. As variáveis analisadas como determinantes para a adoção de estruturas plurais foram: ambiguidade, complexidade e comportamento estratégico.

A segunda etapa teve caráter descritivo, pois, foi feito um levantamento de informações do SAG do leite identificando, por meio de informações disponibilizadas online, características do ambiente em que estão inseridos os agentes que o compõem. Para a realização dessa etapa foram utilizadas as seguintes fontes de dados: a) dados secundários de cadastros industriais, por meio de fontes estaduais e nacionais: Ministério da Agricultura, Pecuária e Abastecimento (MAPA), Secretaria da 
Agricultura do PR, federação de indústrias, associações industriais, etc.; fontes locais e regionais - prefeituras, Emater, Adapar etc.; b) outros bancos de dados sobre o setor, disponíveis em artigos, livros, relatórios de pesquisa; c) demais fontes de dados como: Instituto Brasileiro de Geografia e Estatística (IBGE), Empresa Brasileira de Pesquisa Agropecuária; Instituto de Economia Agrícola (IEA/SP); Centro de Estudos Avançados em Economia Aplicada (CEPEA-Esalq/USP).

A terceira etapa esteve voltada para a seleção dos casos com base no levantamento e mapeamento dos laticínios que possuíam o SIF, para que então fosse realizada as entrevistas com representantes dos laticínios.

A quarta etapa teve como foco a realização das entrevistas que aconteceram entre os meses de agosto a outubro de 2018, com 12 dos 14 laticínios identificados por meio do relatório da Adapar. Dentre os 12 entrevistados, quatro eram sócios proprietários, quatro gerentes/supervisores e quatro eram responsáveis técnicos dos laticínios e que transacionavam diretamente com os produtores. Em três dos laticínios, as entrevistas aconteceram via contato telefônico, devido à dificuldade de agenda de seus representantes, as demais entrevistas foram agendadas e realizadas com visita ao laticínio. As principais informações que foram investigadas por meio da entrevista estão resumidas na Tabela 1.

Tabela 1: Informações coletadas nas entrevistas com os representantes dos laticínios

\begin{tabular}{|c|c|}
\hline Temas de interesse da entrevista & Elementos que compõem o tema \\
\hline $\begin{array}{l}\text { Disponibilidade e escolha de } \\
\text { compradores/fornecedores }\end{array}$ & $\begin{array}{l}\text { Número de empresas disponíveis para transação, tipos de } \\
\text { empresas, serviços oferecidos pelo comprador, presença de } \\
\text { concorrência e como ela interfere na relação entre os } \\
\text { produtores e laticínios }\end{array}$ \\
\hline Negociação & $\begin{array}{l}\text { Produção mensal dos laticínios, quantidade e qualidade do } \\
\text { leite entregue; forma contratual, formas de negociação do } \\
\text { preço, fatores envolvidos na negociação, grau de importância } \\
\text { quanto aos parâmetros definidos pelo comprador; relação com } \\
\text { outros laticínios }\end{array}$ \\
\hline $\begin{array}{l}\text { Relação de confiança com } \mathrm{o} \\
\text { comprador }\end{array}$ & $\begin{array}{l}\text { percentual dos produtores que estão com o laticínio a mais } \\
\text { tempo; histórico de cumprimentos do acordo entre as partes }\end{array}$ \\
\hline Ações oportunistas & $\begin{array}{l}\text { descumprimento de pagamento pelo comprador; necessidade } \\
\text { de contratos, existência deles - como se dão; descumprimento } \\
\text { do acordo com produtor }\end{array}$ \\
\hline
\end{tabular}

Fonte: Resultados da Pesquisa (2018).

A quinta etapa e última etapa consistiu-se em análise dos dados, cujo objetivo foi analisar as informações obtidas por meio das entrevistas e levantamentos bibliográficos. Para realizar a interpretação das informações também se utilizou estatística descritiva, com auxílio do software Excel.

\section{ANÁLISE DOS RESULTADOS}

Uma parte fundamental da análise desenvolvida neste estudo é a caraterização dos agentes e das transações realizadas na atividade leiteira entre os laticínios e produtores de leite. Este tópico tem o objetivo descrever elementos que caracterizam as transações e os agentes. Para isso, nessa etapa será apresentada a análise dos dados que será dividida em duas partes centrais, a primeira voltada para a caracterização das agroindústrias e a segunda voltada para a análise das formas plurais. 


\subsection{CARACTERIZAÇÃO DAS AGROINDÚSTRIAS PESQUISADAS}

Inicialmente buscou-se realizar uma caracterização das agroindústrias de leite da região. Dentre as informações coletadas estão a idade das agroindústrias, a capacidade instalada, as unidades existentes, os mercados atendidos pela indústria, o número de funcionários, a quantidade de fornecedores de leite, o raio de captação, a concorrência e o nível tecnológico dos produtores. Assim, no Gráfico 1 é apresentada a dispersão dos laticínios entrevistados, tornando possível observar que sua maioria é composta por empresas com mais de 20 anos e existência.

Gráfico 1 - Idade dos Laticínios com SIF instalados na região Oeste do Paraná.

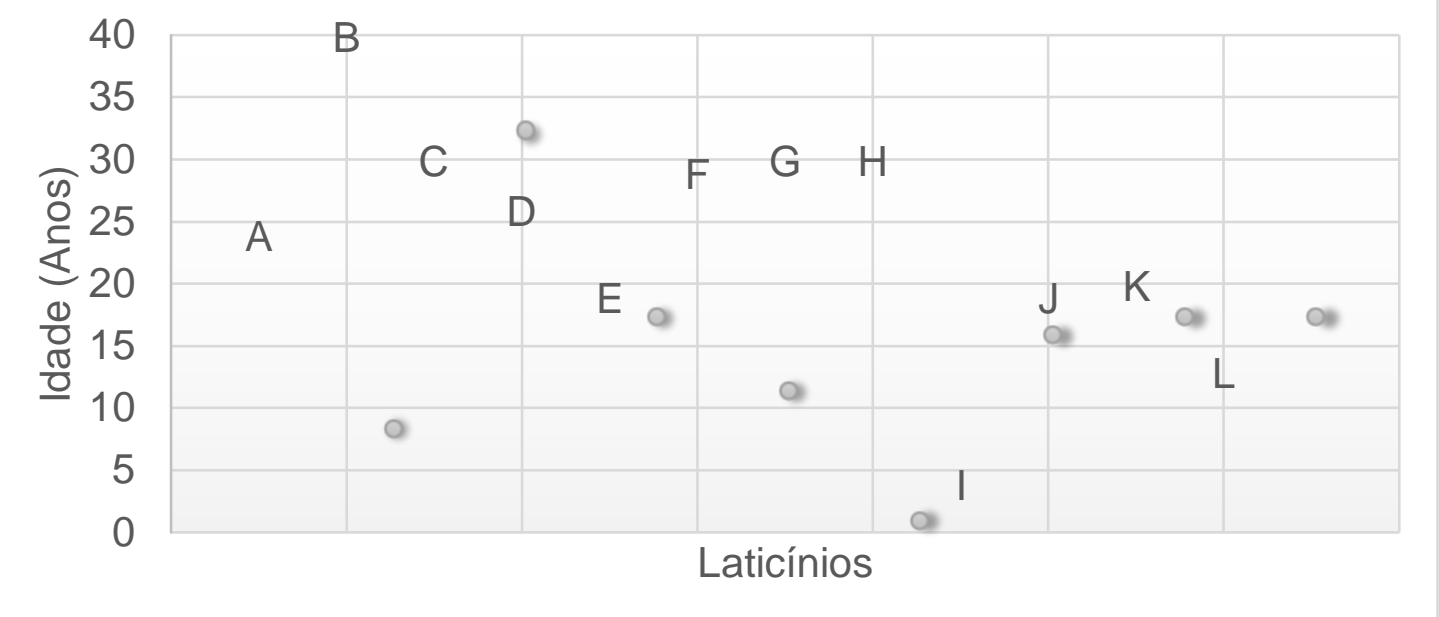

Fonte: Resultados da pesquisa (2018).

Observa-se no Gráfico 1 que 58\% dos laticínios possuem mais de 20 anos no mercado. Essa informação contribui para a compreensão dos determinantes das formas plurais, tais como comportamento estratégico e complexidade. Nesta pesquisa, também se identificou que a média da capacidade ociosa dos laticínios é 35 mil litros/dia e que metade das empresas possui uma produção que está abaixo desse valor. Do mesmo modo, verificou-se que a maioria dos laticínios possui outras unidades, conforme Gráfico 2.

Gráfico 2 - Número de filiais dos laticínios com SIF na região Oeste do Paraná 


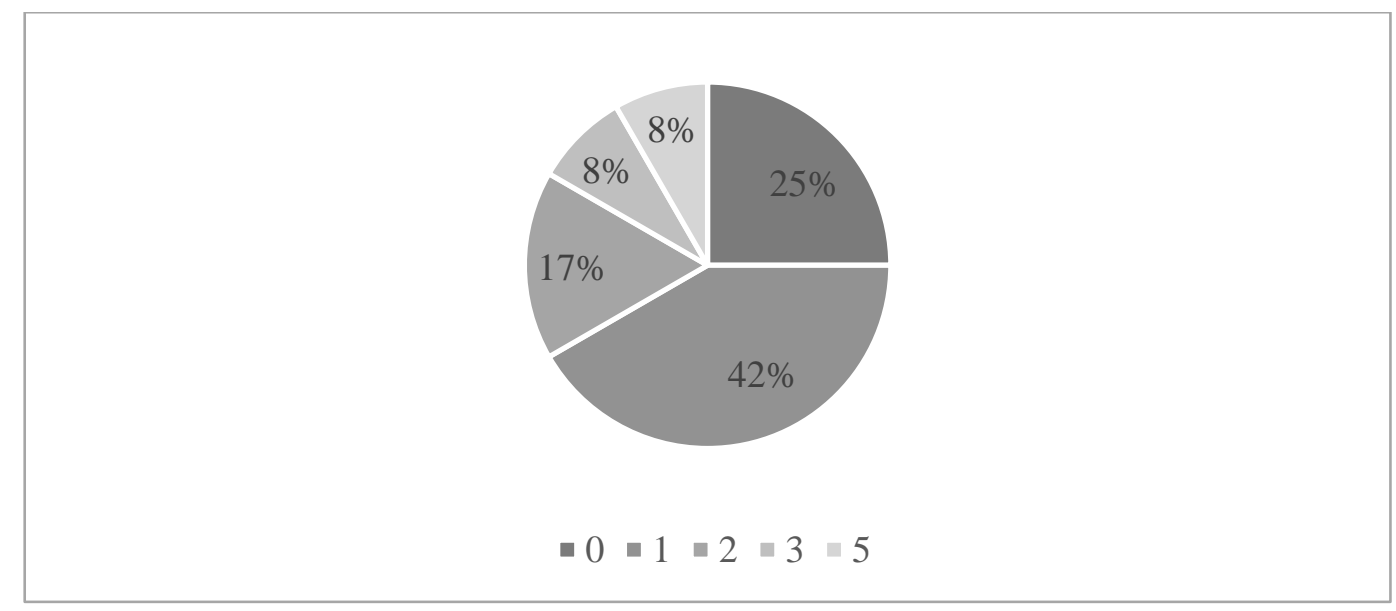

Fonte: Dados da pesquisa.

Observa-se de acordo com o Gráfico 2 que a maior parte dos laticínios (75\%) possui mais de uma unidade processadora, elemento que está relacionado com a estratégia de comercialização de produtos, buscando atender outros mercados. Entretanto, há de se destacar que apenas três laticínios possuem outra unidade na própria região Oeste, os demais estão presentes em municípios no estado de São Paulo, Minas Gerais, Rio de Janeiro, Mato Grosso do Sul, e em outras regiões do Paraná. Outro aspecto que deve ser comentando é que ter mais uma unidade processadora não é um fator presente apenas em laticínios que já estão no mercado a mais tempo, laticínios mais jovens também possuem outras unidades.

Dos mercados atendidos por essas indústrias, São Paulo e Rio de Janeiro são os que apresentam maior intensidade, sendo que dois deles comercializam para o país todo e dois comercializam apenas no Paraná. A média de funcionários que trabalham nas unidades entrevistadas é de 144 pessoas e 90\% dos laticínios apontam estar realizando algum tipo de investimento.

O Gráfico 3 apresenta a distribuição do número de produtores para cada laticínio entrevistado.

Gráfico 3 - Número de produtores por laticínio com SIF na região Oeste do Paraná

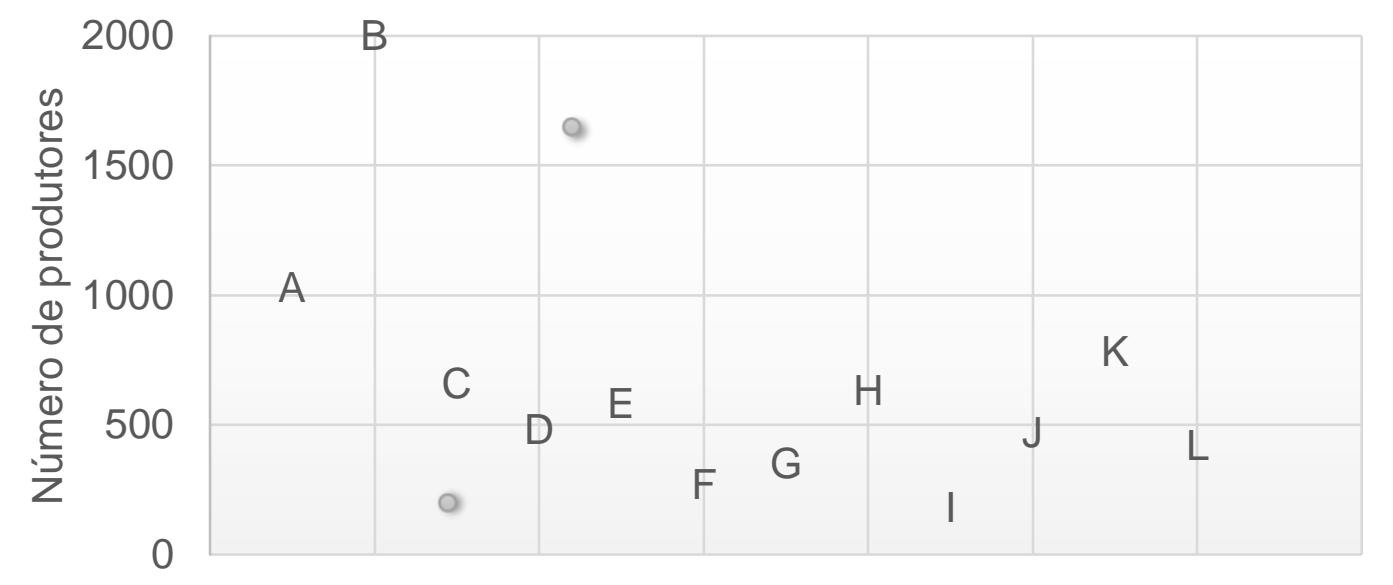

Fonte: Dados da pesquisa.

Os entrevistados destacaram que há uma concorrência grande na região entre os laticínios e que em muitos casos é necessário percorrer longas distâncias para captar leite. Destacaram também que, de modo geral, a produção de leite é uma atividade 
desenvolvida por pequenos produtores, o que contribui para ter um número maior de fornecedores.

Feito essa caracterização do objeto deste estudo, o próximo tópico avança para a análise das transações entre esses agentes envolvidos no SAG do leite, elo processador e produtor da região Oeste do Paraná.

\subsection{ANÁLISE DAS FORMAS PLURAIS}

Essa etapa será subdivida em identificação das formas plurais e, em seguida, análise dos determinantes da escolha das formas plurais.

\subsubsection{Avaliação da existência das formas plurais}

Sobre a presença de contratos na relação produtor e laticínios observou-se que 11 laticínios possuem contratos informais, ou seja, os produtores e os laticínios acordam verbalmente detalhes relacionadas ao produto transacionado, tais como quantidade, qualidade, preço, dentre outros. Dos 11 laticínios que adotam contrato informal, 8 deles possuem esse tipo de contrato com inclusão de serviços. Ou seja, por um lado, os produtores têm contratos informais com os laticínios para a venda de leite, por outro, os laticínios prestam algum tipo de serviço aos produtores, como por exemplo, o financiamento para compra de equipamentos para produção leiteira e a assistência técnica. Em todos os casos, observou-se que as indústrias recorrem à estrutura de mercado spot entre empresas, especialmente quando a oferta de leite é menor.

Em um dos casos estudados, adota-se a estrutura cooperativista, em que uma cooperativa central recebe o leite das cooperativas a ela filiadas. As cooperativas singulares (filiadas) estabelecem uma relação com o produtor com base em suas estratégias, ou seja, cada cooperativa filiada define questões como a adoção de integração, fornecimento de implementos agrícolas e apoio com assistência técnica.

Observou-se a adoção do modelo de integração vertical por um dos laticínios entrevistados, o qual possui produção própria do leite industrializando e comercializando os produtos desenvolvidos. Esse laticínio produz leite tipo A, assim sendo, todo o processo produtivo ocorre na propriedade, desde a produção do leite até o beneficiamento, deixando o produto pronto para retirada da propriedade para comercialização. Logo, não ocorre relação com demais produtores de leite.

A adoção de diversas formas de governança encontradas no setor em análise ocorre devido a possibilidade de se explorar alguma sinergia entre os mecanismos de governança complementares. Diversas são as justificativas para a adoção de formas plurais de coordenação. Alguns autores apontam para a redução dos custos de produção e transação; outros apontam que operação simultânea de vários canais e adoção de diferentes estruturas de governança permitem à firma combinar estratégias aproveitando melhor cada estrutura, podendo também se beneficiar da complementariedade existente entre elas, como já mencionado (SILVEIRA et al., 2014).

Sobre as estruturas adotadas nas transações, o Quadro 1 apresenta um resumo que representa a ocorrência de adoção das formas de obtenção do leite pelos laticínios e as combinações realizadas por eles.

Quadro 1 - Formas de obtenção do leite adotado pelos laticínios da região Oeste. 


\begin{tabular}{|c|c|c|}
\hline Formas de obtenção do leite & $\begin{array}{l}\text { Adoção } \\
\text { pelos } \\
\text { laticínios }\end{array}$ & $\begin{array}{l}\text { Combinações } \\
\text { realizadas }\end{array}$ \\
\hline Produção Terceirizada & $92 \%$ & \multirow{6}{*}{$\begin{array}{l}\mathrm{B}+\mathrm{C}(75 \%) \\
\mathrm{A}+\mathrm{B}(12 \%) \\
\mathrm{C}+\mathrm{D}(12 \%)\end{array}$} \\
\hline Fornecedores relacionais (sem contrato formal) (C) & $92 \%$ & \\
\hline Total de adoção das formas plurais & $66 \%$ & \\
\hline Mercado spot (B) & $25 \%$ & \\
\hline Fornecedores com contrato formal (D) & $16 \%$ & \\
\hline Produção Própria (A) & $8 \%$ & \\
\hline
\end{tabular}

Fonte: Resultados da pesquisa (2018).

A produção terceirizada está presente em 92\% dos estabelecimentos analisados correspondendo a 11 dos 12 casos estudados enquanto, apenas 8\%, ou seja, 1 laticínio produz seu próprio leite. Observa-se que os laticínios combinam as estruturas de governança para aquisição do leite, desse modo a aquisição de leite via mercado, por exemplo, ocorre em 25\% (3 laticínios) dos estabelecimentos entrevistados. Isso serve para a análise dos demais, em que os contratos informais predominam esse modelo de aquisição 92\%, presente em 11 casos. Por fim os contratos formais que acontecem em $16 \%$ dos laticínios entrevistados. Observou-se então que a maior parte dos laticínios adquire o leite via fornecedores relacionais ou contratos informais.

Isso permitiu verificar que 8 dos 12 dos laticínios da região adotam estruturas plurais, correspondendo a 88\%. As combinações de estruturas adotadas simultaneamente mais frequentes são: a transação por meio de mercado spot e fornecedores relacionais $(B+C)$, representando $75 \%$; na sequência, tem-se e a aquisição via produção própria e mercado spot $(A+B)$ e fornecedores relacionais e contratos formais $(\mathrm{C}+\mathrm{D})$, ambas as combinações com $12 \%$.

Sobre aquisição via produção própria e mercado spot e fornecedores relacionais e contratos formais, estão relacionados com a origem do empreendimento, pois são empresas familiares cujo início dos trabalhos se deu a partir da propriedade rural. Nesse ponto, essa modalidade não demonstra uma estratégia deliberada de diversificação da modalidade de captação de leite para processamento. Entende-se que a motivação para essa modalidade esteja relacionada com a complexidade, isso porque a indústria processadora está mantendo o padrão de produção já realizado. Nessa escolha de arranjo, estão sendo considerados os custos irrecuperáveis (sunk cost), o que pode servir como um ponto de referência para subsidiar a negociação com seus fornecedores.

Do outro lado, tem-se a presença em quase todas as transações da aquisição de leite via contrato relacional, constatando-se relações de longo prazo mantidas entre os produtores e os laticínios. Os laticínios declaram que em média 50\% dos produtores transacionam com laticínio a mais de 5 anos, em alguns casos, 20\% desde que o laticínio abriu, sendo que a média de idade dos laticínios entrevistados é de 22 anos.

Outro ponto que pode ser analisado é o fato de que $42 \%$ dos laticínios declararam fornecer apoio técnico para os produtores. No entanto, parte do custo desse suporte técnico é custeada pelo produtor. O profissional responsável pelo suporte técnico passa a representar neste cenário um canal de relacionamento importante para a empresa, além de monitorar o assédio de compradores e novos concorrentes no mercado, conforme destacado pelo gestor de um dos laticínios participantes do estudo (Entrevistado 1): "O técnico nos ajuda com o produtor a saber como ele e sua família estão, o produtor confia no técnico e acabam desenvolvendo uma relação de confiança onde o produtor conta para o técnico quando recebe visita de outros laticínios".

Ainda, é apontado por todos os entrevistados, exceto o que estão sob integração, que a aquisição do leite via contrato informal não fornece nenhuma salvaguarda 
quanto a parâmetros como, por exemplo, volume e padrões de qualidade. Em parte, isso também é reflexo da grande concorrência presente na região. Todavia, o que é importante destacar é que a ausência de padrões superiores de qualidade impossibilita os laticínios de desenvolverem produtos com valor agregado. Isso pode ser observado pelo mix de produtos desses laticínios, sendo que $75 \%$ deles tem todo seu volume de leite destinado para produção de queijos, especialmente muçarela, queijo esse que não necessita de padrões superiores de qualidade do leite para sua produção.

\subsubsection{Fatores determinantes para as escolhas das formas plurais}

Nesse estudo, a compreensão da escolha de qual será o arranjo da transação diante da pluralidade de formas de governança é feita com base na análise do padrão de transação (aquisição do leite) quanto a três variáveis: a) ambiguidade, b) complexidade e c) comportamento estratégico. Assim, esse tópico estará destinado à compreensão dos determinantes da escolha com base nessas variáveis.

Primeiramente, a ambiguidade está relacionada com a dificuldade que os agentes têm em avaliar de maneira correta os benefícios esperados ao lidar com características das transações. Ela pode ser determinada pela imprevisibilidade da oferta e demanda, sendo esse ponto elemento chave na sua determinação, isso porque a solução disponível para enfrentar tal situação levaria à condição ou não de se manter compromisso (SILVEIRA et. al, 2014).

O que se identificou referente a essa variável no estudo desenvolvido é que há ambiguidade na transação. A previsão de oferta do leite, devido à grande concorrência que existe na região e fora dela, fica prejudicada, pois os laticínios não conseguem prever com exatidão qual volume e quantos produtores de leite serão seus fornecedores no mês seguinte, o que aumenta o risco e dificulta o planejamento dos laticínios.

Sobre a comercialização, aproximadamente 90\% dos laticínios entrevistados comercializam seus produtos em outros estados, principalmente, São Paulo, Rio de Janeiro e Minas Gerais. Isso, segundo os entrevistados, deve-se ao volume de consumidores presentes nesses grandes centros, um fator que pode estar relacionado a esta questão é a ausência ou a dificuldade de acesso a informações regulares que mostrem as tendências de consumo de lácteos nas regiões.

Além da ambiguidade, a complexidade é também uma das características das transações adotadas pelos agentes. Essa, está relacionada com as características tecnológicas ou organizacionais da transação que uma parte tem de organizar; trata-se da possibilidade de existência de incertezas sobre a forma mais adequada para monitorar determinada operação, não se tratando unicamente da avaliação dos ativos específicos no que se refere ao monitoramento da transação (MÉNARD, 2014). Há um alto risco em adotar apenas uma forma de governança em transações complexas, aumentando os custos de transação e podendo tornar as firmas ineficientes. Neste caso, a adoção de formas plurais de governança poderia ser uma solução para mitigar o risco gerado pela complexidade da transação (SILVEIRA et al., 2014).

Assim, alguns pontos são utilizados para análise da presença dessa variável nos casos estudados. O primeiro deles está relacionado à base tecnológica adotada pela empresa processadora no que se refere às unidades instaladas na região. A maior parte delas apresenta a mesma base para produção de queijos, mas de tipos diferentes (tipo prato, muçarela, suíço, requeijão, coalho e outros), $75 \%$ delas produzem os mesmos produtos.

Outro aspecto se refere aos padrões de qualidade estabelecidos pelos laticínios de modo que esses tenham um grau de especificidade alto, como vacas de um tipo específico, realização de inseminação, um tipo único de nutrição, dentre outros.

Informe GEPEC, ISSN: 1679-415X, Toledo, v. 25, n.1, p. 240-260, jan./jun. 2021. 
Nenhum dos laticínios entrevistados estabelece padrões como os citados anteriormente, sendo que a única especificação definida por todos os laticínios entrevistados é que o leite atenda aos parâmetros sanitários estabelecidos pela Instrução Normativa 62. Alguns desses pontos estão relacionados com a complexidade da transação e a necessidade do agente em monitorar a transação.

Desse modo, percebe-se que os parâmetros analisados para variável complexidade não apresentam poder explicativo para a escolha dos mecanismos de governança adotados pela maior parte das empresas analisadas. No entanto, essa condição é totalmente justificada quando se observa adoção de estruturas de governança que possuem produção própria, apresentando relação com características presente na variável complexidade. Ainda assim, entende-se que as transações de compra de leite pela indústria processadora são frequentes e ocorrem num ambiente marcado pela incerteza ligada à assimetria de informações.

No que se refere à frequência, observa-se a necessidade de renegociação mensalmente marcada por um contrato informal sem salvaguarda entre as partes, característica presente em $85 \%$ dos casos. Outras características constatadas são em relação à variação de preços, especificidades e necessidade de garantir regularidade no volume processado - minimizando a capacidade ociosa da planta - aproveitando as economias de escala, para obtenção de consistência na qualidade de leite processado, reduzindo os riscos de ações oportunistas por parte dos fornecedores. Consequentemente, a adoção de condições em que a teoria indica o emprego de governanças, pode-se promover um nível maior de controle.

No entanto, observa-se também que as empresas processadoras não conseguem realizar o controle/monitoramento dessas relações devido às questões instáveis no ambiente institucional. Isso gera maior necessidade de controle e fiscalização dos órgãos responsáveis por garantir o atendimento dos padrões estabelecidos na legislação. Isso pode ser registrado conforme o que foi dito por um dos gestores dos laticínios entrevistados para o presente estudo: "É necessário que seja realizada mais fiscalização, é preciso ser alguém de "fora" para autuar e controlar esses padrões, está muito "solto" e a gente sabe os laticínios que não cuidam desses padrões e ainda concorrem conosco no mercado" (ENTREVISTADO 2).

Enquanto esse controle não for realizado, segundo os laticinistas, não se consegue obter maior monitoramento e controle da transação, porque também permite a entrada na atividade de empresas que não atendem a exigências e que concorrem no mesmo mercado.

Com relação a terceira e última variável, o comportamento estratégico, observase a presença do mesmo quando uma das partes estabelece uma estrutura de governança, por meio de um arranjo plural para capturar o máximo possível da renda, quando há problemas de observação e/ou verificação do comportamento do parceiro e/ou mensuração da qualidade do bem transacionado. A dificuldade da empresa em obter informações e mensurar o poder relativo dos agentes da transação podem ser fatores motivadores para o comportamento estratégico (MENARD et al., 2014; SILVEIRA et al., 2015).

Desse modo, com base nas informações coletadas no presente trabalho, destacam-se alguns fatores contribuem para a explicação do comportamento estratégico das empresas processadoras em prol da pluralidade, sendo eles: a) escala de produção, em que a média dos laticínios estudados é de 300 mil litros/dia, possuindo laticínio com capacidade de processamento de até 1 milhão de litros de leite por dia; b) estratégia de crescimento da empresa (atuação em outros estados e busca por ganhos de Market Share) observando-se que apenas dois laticínios não comercializam seus produtos em outro estado e; c) poder de barganha dos

Informe GEPEC, ISSN: 1679-415X, Toledo, v. 25, n.1, p. 240-260, jan./jun. 2021. 
fornecedores, em especial aos grandes produtores, mais especializados, que exercem poder de barganha na negociação de fornecimento de leite cru e são considerados formadores de opinião para os pequenos produtores.

Esses produtores são minoria, mas são fundamentais para o laticínio, já que reduzem os custos logísticos por possuírem maiores volumes em uma única propriedade, conforme observado por outro gestor de laticínio entrevistado na pesquisa: "Nós tentamos sempre negociar com o produtor que tem bom volume para continuar mantendo ele conosco, mesmo quando descobrimos que tem outro laticínio rondando, pois eles contribuem com bom volume para processar" (ENTREVISTADO $3)$.

Assim, a escala de produção/crescimento da firma, as características do produto (sazonalidade, perecibilidade), a dispersão dos fornecedores no espaço geográfico e o poder de barganha dos grandes produtores podem introduzir desafios adicionais no que diz respeito ao controle e à própria coordenação da produção. Deste modo, observa-se que as empresas processadoras empregam governanças diferentes para coordenar suas transações porque essas transações são diferentes em pelo menos um dos atributos: especificidade de ativos, frequência ou incerteza.

Sob o enfoque das Formas Plurais, a coordenação das estruturas se dá via produção própria e produção terceirizada, esta última compreendendo: mercado spot, contratos relacionais e contratos formais. Quanto as estruturas em que a há produção própria (integração vertical), a complexidade é um dos elementos que se destaca pela necessidade de controle e monitoramento das operações, além de questões vinculadas a incerteza e a especificidade dos ativos envolvidos.

Quanto à produção terceirizada, observa-se a ambiguidade em que os graus dos ativos específicos não são avaliados com precisão, de maneira que seja possível aferir os benefícios das estruturas utilizadas e do controle do seu uso. Além dessa variável, destaca-se também o comportamento estratégico dos agentes, estando relacionado com capacidade de verificação e observação do comportamento dos parceiros, ou da mensuração do bem transacionado. Isso pôde ser concluído com baseando-se nos seguintes elementos: à incerteza quanto ao fornecimento de leite (principalmente atrelado à alta concorrência e ausência de contratos formais entre as partes); a baixa exigência de parâmetros (qualidade, nutrição, distância e outros) definida pelos laticínios aos produtores; e a fabricação de produtos commoditizados desenvolvido pelo laticínio (muçarela, prato, minas frescal), que não apresentam uma agregação de valor como queijos especiais (brie, gongorzola, provolone) ou iogurte dentre outros.

Os entrevistados destacaram ainda, a presença de concorrentes dentro da própria região. Apontam que a concorrência sempre existiu, mas que acreditam estar aumentando nos últimos anos, especialmente pela saída de alguns produtores da atividade, o que gera a procura de todos os laticínios por produtores. Isso também dificulta que os laticínios definam padrões de exigência aos produtores, conforme menciona um dos representantes dos laticínios participantes do estudo. "Se exigirmos muito do produtor, do jeito que tá a concorrência ele troca de laticínio" (ENTREVISTADO 4).

Quando questionados sobre a adoção de contratos formais, eles destacaram que esse método seria muito bom para garantir o volume de produção, mas os produtores não aceitariam, porque perderiam a liberdade de negociar maiores valores com outros laticínios quando o preço do leite sobe. Outro ponto interessante é que alguns entrevistados disseram que o produtor não cumpriria o contrato, conforme menciona o Entrevistado 5: "Mesmo que houvesse a adoção de contrato ele não cumpriria, e quem ia exigir que ele comercializasse para mim mesmo assim? ” 
Assim, esses pontos contribuem para a presença, principalmente de ambiguidade e comportamento estratégico na produção terceirizada. Isso pode ser abordado levando em consideração que os laticínios estudados são registrados no SIF, logo, espera-se maior qualidade ao longo do tempo. Para manter essas exigências, o comportamento estratégico principalmente para a captação de produtos terceirizados pode ser um mecanismo de sobrevivência para as empresas, diante da especificidade da qualidade imposta a essas empresas. A especificidade resultante do registro no SIF impacta nas relações entre o elo processador e produtor, ao exigir que a empresa adote medidas para maior eficiência e qualidade desde o início do processo produtivo.

Desse modo, o que se observa é que a adoção das formas plurais proporciona sinergias para a firma, ocasionando redução dos custos de transação, aumentando o desempenho. A dificuldade da firma em obter informações e mensurar o poder relativo dos agentes nas transações pode ser um elemento motivador para o comportamento estratégico. Todavia, a adoção de formas plurais pode reduzir esse risco, pois as firmas podem encontrar diferentes soluções para governar transações semelhantes, diferentemente do equilíbrio único que decorre da adoção de forma de governança minimizadora dos custos de transação, conforme proposta de Williamson (1991). Ainda que Williamson não tenha tratado em seus estudos a possibilidade de as firmas utilizarem mais de uma estrutura de governança simultaneamente, Bradach e Eccles (1989) constataram tal fenômeno, o qual chamaram de formas plurais.

Sobre as formas plurais serem estáveis ou transitórias, embora esse ponto não tenha sido diretamente explorado pela pesquisa, algumas inferências foram possíveis, em decorrência das informações coletadas durante o contato realizado nos laticínios. Não existe uma única classificação possível, ou seja, as formas plurais serão estáveis enquanto as condições do ambiente e da transação assim permitirem, diante de alterações ou choques no ambiente, tais como, mudança na legislação, exigência de qualidade, demanda, entre outros, as formas irão se estabilizar. Logo, pode ser que em determinado período as formas pareçam estáveis, mas, no decorrer de $n$ tempo, poderá ser verificada a existência de formas transitórias. Com isso, a combinação dos elementos para escolha de qual forma irá coordenar a transação será de acordo com elementos que possam permitir maior competitividade do SAG do leite naquela região.

\section{CONCLUSÕES}

Os principais resultados apontam que as características da atividade leiteira na região Oeste do Paraná apresentam pluralidade de formas para aquisição do leite, sendo as mais regulares: Mercado spot + Contrato Relacional; Contrato Relacional + Contrato formal; Produção Própria + Mercado spot. A aquisição ocorrida com maior frequência é a estrutura de Mercado spot e Contrato Relacional.

A explicação para a pluralidade decorre especialmente da constatação de que os laticínios apresentam escala de produção, não podendo correr o risco de operar com alta ociosidade, devendo otimizar sua estrutura produtiva para garantir uma adequada oferta de matéria-prima ao longo do tempo. Assim, é plausível que a firma procure estabelecer mais de uma forma de aquisição de leite, buscando minimizar a incerteza.

A incerteza é proveniente da possibilidade de perda de fornecedores, devido à alta concorrência entre os laticínios, que gera poder de barganha com os fornecedores, principalmente com os grandes produtores. Com isso, a pluralidade de formas de captação de leite permite à empresa dividir os riscos entre as diferentes modalidades adotadas, garantindo a oferta da matéria prima e contribuindo para o incremento de sua participação no mercado. 
Pode-se concluir com base nesse estudo que a adoção das formas plurais por parte significativa dos laticínios, (66\%) apresenta-se como estratégia assertiva de coordenação das transações para aquisição de leite, dada a maior flexibilidade propiciada por esse modelo. Entretanto, gargalos no setor de laticínios ainda são perceptíveis e requerem, talvez, um olhar mais apurado por parte dos agentes e demais estudiosos do setor para que soluções viáveis possam ser implantadas, para além da forma de coordenação das transações existente.

Há que se considerar algumas limitações que existiram no decorrer deste trabalho, tais como as entrevistas terem sido realizadas apenas com os integrantes dos laticínios que estavam registrados no SIF. Assim, salienta-se necessidade de novos estudos ampliando o número de laticínios e capturando informações de outros agentes envolvidos na transação, tais como os produtores e laticínios que comercializam via mercado spot, podem permitir uma análise mais ampla sobre a realidade. Acredita-se que analisar as informações de outros agentes que compõem a Cadeia produtiva ou até mesmo o SAG no leite, seriam possibilidades de estudos profícuos.

Agradeço a bolsa de estudos do Conselho Nacional de Desenvolvimento Científico e Tecnológico - CNPq e ao suporte institucional do Parque Tecnológico Itaipu - Brasil - PTI. 


\section{REFERÊNCIAS}

ADAPAR - Agência de Defesa Agropecuária do Paraná. Perfil de Classificação POA, Disponível em:

https://www.reida.adapar.pr.gov.br/daeda/manterEmpresaPOA

ClassificacaoPublico.do?action=consultar>. Acesso em 21 de jan. 2018.

BRASIL. Decreto $\mathrm{n}^{0} 1.812$ de o8 de fevereiro de 1996. Regulamento Técnico de Identidade e Qualidade do Leite UAT (UHT). Brasília, DF. Fev. 1996.

BRASIL. Decreto no 9.013. Disponível em: <http://www.planalto.gov.br/ccivil_03/ _ato2015-2018/2017/decreto/D9013.htm>. Acesso em 26 jan. 2018.

BREITENBACH, R. Estrutura, Conduta e Governança na Cadeia Produtiva do Leite: Um Estudo Multicaso no Rio Grande do Sul. 2012. 272 f. Tese (Doutorado) - Curso de Extensão Rural, Universidade Federal de Santa Maria - RS, Santa Maria, 2012.

CAMPEÃO, P. Sistemas Locais de Produção Agroindustrial: um modelo para a competitividade. 2004. 230 f. Tese (Doutorado) - Engenharia de Produção. Universidade Federal de São Carlos, São Carlos, 2004.

COASE, R. The nature of the firm. Economia. Nex Series, v.4, n. 16, p. 386-405, nov. de 1937.

EMBRAPA - Empresa Brasileira de Pesquisa Agropecuária. Embrapa Gado de Leite. (2018). Disponível em: https://sistemasdeproducao.cnptia.embrapa.br/ FontesHTML/Leite/LeiteSudeste/racas.html >. Acesso em o1 de set. 2018.

INSTITUTO BRASILEIRO DE GEOGRAFIA E ESTATÍSTICA (IBGE). Pesquisa da Pecuária Municipal e Censo Agropecuário. Rio de Janeiro: SIDRA, 2016. Disponível em: <www.sidra.ibge.gov.br>. Acesso em o8 jan. 2018.

INSTITUTO BRASILEIRO DE GEOGRAFIA E ESTATÍSTICA (IBGE). Pesquisa Trimestral do leite. Rio de Janeiro: SIDRA, 2020. Disponível em: <https://sidra.ibge.gov.br/home/leite/brasil>. Acesso em 11 nov. 2020.

INSTITUTO PARANAENSE DE DESENVOLVIMENTO ECONÔMICO E SOCIAL (IPARDES). Base de dados. Disponível em: < www.ipardes.com.br $>$. Acessado em 20 de jan. 2018.

INTELACTUS - EMBRAPA. Plataforma de Inteligência Estratégica e Competitiva do Leite. Indicadores: Leite e Derivados. Ano 8, n. 73. Juiz de Fora: Embrapa Gado de Leite, 2017.

INTELACTUS - EMBRAPA. Plataforma de Inteligência Estratégica e Competitiva do Leite. Indicadores: Leite e Derivados. Ano 9, n. 73. Juiz de Fora: Embrapa Gado de Leite, 2018. 
MAPA. SIF. Brasil. Disponível em: <https://www.gov.br/agricultura/ptbr/assuntos/inspecao/produtos-animal/sif>. Acesso em 11 de nov. 2020.

MARTINS, P. do C. Políticas públicas e mercados deprimem o resultado do sistema agroindustrial do leite. Embrapa Gado de Leite Juiz de Fora, Minas Gerais, 2004.

MÉNARD, C. Formas Plurais de Organização: Onde estamos? In: MÉNARD, C. (Org.). Economias das organizações: formas plurais e desafios. São Paulo: Atlas, 2014. Cap. 3. p. 52-70.

MÉNARD, C.; SAES, M. S. M.; SILVA; V. L. DOS S.; RAYNAUD, E (Org.). Economia das Organizações: formas plurais e desafios. São Paulo: Atlas, 2014.

MENDES, A. S. Estruturação e desafios do setor de produção de leite. In: CASTRO, M. C. D.; MARTINS, P. do C. (eds.) Organização da produção primária: um desafio para a indústria de laticínios. Juiz de Fora. Epamig/ILCT.1999. p.4044 .

SCHNAIDER, P. S. B.; RAYNAUD, E.; SAES, M. S. MA. O Fenômeno das Formas Plurais. In: MÉNARD, C. (Org.). Economias das organizações: formas plurais e desafios. São Paulo: Atlas, 2014. Cap. 2. p. 35-51

SILVEIRA, R. L. F. DA; CARRER, M. J.; CARVALHO, T. B.; FOSCACHES, C. A. L.; SAES, M. S. M. Formas Plurais de Governança: uma análise das transações de suprimento entre frigoríficos e pecuaristas. RESR, Piracicaba - SP, Vol. 52, No 04, p. 761-782, Out/Dez 2014.

SEAB/DERAL. Área e produção - Resumo Estadual. Disponível em: <http://www.agricultura.pr.gov.br/deral/safras>. Acesso em 11 de nov. 2020. SOUZA, J. P. de; PEREIRA, L. B. A coordenação e a articulação na cadeia de laticínios do Paraná. In: PRADO, I. N. do; SOUZA, J. P. de (Org.). Cadeias produtivas estudos sobre competitividade e coordenação. 2. ed. Maringá: Eduem, 2009. Cap. 8. p. 173-192.

WILLIAMSON, O. E. Comparative Economic Organization: The Analysis of Discrete Structural Alternatives. Administrative Science Quarterly, Vol. 36, N ${ }^{\circ}$ 2, p. 269-296, Jun. 1991.

ZANELLA, C. Determinantes da estrutura de governança na cooperativa central aurora alimentos (aves) - formas plurais e não plurais: uma análise a partir dos custos de transação, custos de mensuração e recursos estratégicos. 2017. 371 f. Tese (Doutorado) - Curso de Programa de Pós-Graduação em Administração, Universidade Federal de Santa Catarina, Florianópolis, 2017.

ZOCCAL, R. Mercado de lácteos no Brasil: produção, importação e exportação. (2017). Disponível em: < http://www.baldebranco.com.br/mercado-delacteos-no-brasil-producao-importacao-e-exportacao/>. Acesso em 20 de set. 2018. 


\section{Sobre o(s) Autor(es):}

\section{Victoria Maria Ferreira Diniz}

Mestre em Desenvolvimento Regional e Agronegócio na Universidade Estadual do Oeste do Paraná. Possui graduação em Administração UDC/FGV. Técnica em Gestão de Agronegócios (Ensino Médio Integrado ao Técnico) pelo Instituto Federal do Tocantins. Professora na Universidade do BioparkParque Científico e Tecnológico de Biociência e professora conteudista na DTCOM. Atuou no Parque Tecnológico Itaipu - BR como analista de desenvolvimento territorial. Possui experiência profissional nas áreas de análise de dados e informações socioeconômicas, planejamento, desenvolvimento de projeto, articulação e organização de agendas estratégicas, além de desenvolvimento de conteúdo. Email: victoriadiniz2@gmail.com

\section{Carla Maria Schmidt}

Pós doutora pela FURB. Doutora em Administração pela Universidade de São Paulo (FEA/USP). Docente do programa de pós-graduação em Desenvolvimento Regional e Agronegócio e do curso de Secretariado Executivo Trilíngue da Universidade Estadual do Oeste do Paraná (Unioeste). Líder go Grupo de Pesquisa GPSEB. Email: carlamariaschmidt@hotmail.com

\section{Ivanete Daga Cielo}

Doutora em Desenvolvimento Regional e Agronegócio pela Universidade Estadual do Oeste do Paraná - UNIOESTE (2015) e mestre em Engenharia de Produção pela Universidade Federal de Santa Catarina (2001). Possui graduação em Secretariado Executivo Bilíngue pela Universidade Estadual do Oeste do Paraná (1994) e especialização em Desenvolvimento Gerencial, também pela UNIOESTE. É professora adjunta da Universidade Estadual do Oeste do Paraná, atuando no curso de graduação em Secretariado Executivo e na pós-graduação lato sensu em Assessoria Executiva. Desenvolve pesquisas nas áreas de secretariado, gestão, agronegócio e empreendedorismo. Email: ivadcielo@hotmail.com 